\title{
Um legendário à saída de Trento (Frei Diogo do Rosário, 1567)
}

\author{
Cristina Sobral \\ csobral@campus.ul.pt \\ Universidade de Lisboa
}

Recepción: 06/12/2016, Aceptación: 10/01/2017, Publicación: 22/12/2017

\begin{abstract}
Resumo
Depois do Flos Sanctorum de 1513, o primeiro legendário per circulum anni que se publicou em português foi a Historia das vidas e feitos heroicos e obras insignes dos sanctos (Braga, Antonio de Mariz, 1567). Apenas quatro anos passados sobre o encerramento do Concílio de Trento e antes mesmo do breviário reformado (1568), o novo legendário foi cometido por Fr. Bartolomeu dos Mártires, Arcebispo de Braga, Primaz das Espanhas e assistente em Trento, ao dominicano Fr. Diogo do Rosário, com o explícito objectivo de substituir as "historias das vidas dos sanctos» que andavam «impressas em vulgar»e que continham «algúas cousas muy incertas e apocriphas» (Fr. Diogo do Rosário, no "Proemio»). Procura-se mostrar alguns dos critérios que presidiram à constituição deste legendário, avaliar as relaçôes que ele estabelece com a tradição medieval e hispânica representada pelo Flos Sanctorum de 1513 e saber em que medida foram acolhidas as recomendaçóes de Trento e se elas se reflectem ou nâo num progressivo "estreitamento» do discurso hagiográfico.
\end{abstract}

Palavras-chave

hagiografia; Trento; legendário; Flos Sanctorum

\begin{abstract}
A legendary after Trento (Frei Diogo do Rosário, 1567)

After the Flos Sanctorum of 1513, the first legendary per circulum anni published in Portuguese was the Historia das vidas e feitos heroicos e obras insignes dos sanctos (Braga, Antonio de Mariz, 1567). A mere four years after the Council of Trent's closing and even before the reformed breviary (1568), the new legendary was ordered by Friar Bartolomeu dos Mártires, Archbishop of Braga, Primate of Hispania and a participant of
\end{abstract}


Trent, to the Dominican Friar Diogo do Rosário, with the explicit goal of replacing the histories of the lives of saints that were printed in Portuguese and which contained some very uncertain and apocryphal matters (Friar Diogo do Rosário, in "Proemio"). This paper attempts to demonstrate some of the criteria that presided over the making of this legendary and to evaluate the connections it establishes with the medieval and Hispanic tradition represented by the Flos Sanctorum of 1513. It also aims to ascertain the manner in which the Trent recommendations were received and whether or not they reflect a progressive narrowing of the hagiographic discourse.

\section{Keywords}

hagiography; Trent; legendary; Flos Sanctorum

\section{Um legendário em 1567}

É costume considerar, no panorama da hagiografia portuguesa, o reinado de D. Manuel (1495-1521) como uma fronteira, uma arrumação do diversificado mundo religioso medieval, oposto ao "progressivo encerramento decorrente do Concílio de Trento, que entre nós teve uma pronta recepção» (Rosa 2000: 346). No âmbito hagiográfico, ela materializa-se na publicação, em 1567, de um novo legendário, antes mesmo do breviário reformado (1568).

Presente no seu terceiro período (1562-1563), o arcebispo de Braga Fr. Bartolomeu dos Mártires (1514-1590) foi uma das figuras de destaque no Concílio de Trento (Jedin 1981: 64-65, 74, 107, 130-1, 220, 235, 261, 272, 274, 292; Barbosa 1991: 33-38), onde defendeu a exemplaridade dos prelados, cujas virtudes principais são pobreza e eficácia na assistência pastoral e cuja instrução deve ser assegurada. O retrato do bispo ideal que desenhou no seu Stimulus Pastorum (Barbosa 2003: 41) serviu de inspiração a S. Carlos Borromeu e aos padres conciliares para a aprovação de medidas sobre a redução de benefícios eclesiásticos, a obrigação de residência dos bispos e a criação de seminários diocesanos. 
Fr. Bartolomeu participou na aprovação dos decretos sobre a veneração de imagens e dos santos. Como é sabido, o Concílio responde às questóes colocadas pelo luteranismo afirmando que a invocaçáo dos santos é boa e útil e que as suas relíquias são dignas de veneração (Canones, et Decreta... 137; Jedin 1981: 279). As imagens conservam a função pedagógica que a Idade Média lhes atribuíra: são úteis na pregação porque lembram aos fiéis os benefícios divinos e suscitam o desejo de imitação (Canones, et Decreta... 137v; Jedin 1981: 280). Por isso mesmo não podem conter erros nem representar objetos profanos ou imorais e devem abster-se do insólito. Novos milagres e novos cultos devem ser encarados com prudência e exigem aprovação episcopal (Canones, et Decreta... 138v). Quanto à reforma do breviário e do missal, o Concílio cometeu-a ao papa, mas deixou consignadas orientações: eliminação de elementos nos prefácios, sequências, hinos e hagiografias procedentes da piedade privada e dos claramente lendários, diminuição das festas dos santos, das missas votivas e de defuntos, a favor do antigo calendário romano, rubricas com caráter obrigatório geral (Jedin 1981: 370).

A publicação em Portugal dos decretos conciliares é quase imediata (1564) e Fr. Bartolomeu dos Mártires não perde tempo em prover o seu clero dos instrumentos necessários para a reforma. Assegura a instrução com o primeiro seminário bracarense e, no mesmo ano em que regressa a Portugal, faz imprimir um novo Cathecismo ou doutrina christãa... (Ferreira 1924: II, 191). No ano seguinte recorre à colaboração de Fr. Diogo do Rosário, seu confrade dominicano, para a publicação de uma Summa caietana tresladada em portugues. Dois anos depois é a vez do novo legendário, compilado pelo mesmo colaborador: Historia das vidas \& feitos heroicos \& obras insignes dos sanctos. Organizado per circulum anni, em dois volumes, os seus princípios são expostos no Proemio (páginas não numeradas):

INota pio leitor que nas historias das vidas de sanctos que andam impressas em vulgar, ha y muitas falhas: e hũa he, que trazem escriptas algũas cousas muy incertas e apocriphas. Polo que pareceo bem ao senhor Arcebispo que ja que se auia de imprimir este liuro, fosse reuisto e emendado, como zeloso de todo bem e proueito as almas. [...] Polo qual trabalhey quâto pude por lançar fora todo ho apocripho e duuidoso, e trazer diante hos lugares onde ho tirey, pera que com mayor gosto e credito leam as historias dos sanctos e se entreguem a elas. E principalméte trabalhey de seguir ho insigne varam e doctissimo Aloysio Lipomano bispo Ueronense, a quem a ygreja deue honra e louuor por suar tanto por este negoceo tam importante, mayormente nestes nossos tempos tam perigosos.

Ajuntey tambem muitas vidas de sanctos que tee agora nam vieram a luz na nossa lingoa Portugues: e muitas tambem deixey de traduzir (nam sem grande dor da minha alma): porque presumir de por em breue volume a infinidade dos béaueturados que a ygreja té, seria notoria temeridade [...]

gReparti este liuro em duas partes, por que se fosse grande volume se pudesse encadernar cada hũa per sy [...]

A bondade dos exemplos dos santos, tal como Fr. Diogo a apresenta, segue os princípios de Trento e continua a tradição medieval. Tal como as imagens, as vidas 
dos santos são úteis como matéria predicável e, em geral, na exortação pastoral, porque acendem e inflamam a seguir as passadas dos que conquistaram a glória. É por isso que a publicação da obra se integra naturalmente na série de instrumentos com que o Arcebispo de Braga deu execução à reforma tridentina. Quanto às «historias das vidas de sanctos que andam impressas em vulgar», elas são, inevitavelmente, aquelas que contém o chamado Flos Sanctorum de 1513 (Biblioteca Nacional de Portugal Res. 157 A; Bitagap Manid 1021). De facto, não há notícia atendível de nenhuma outra impressão de vidas de santos com a qual Fr. Diogo pudesse identificar o seu legendário a ponto de considerar que está a publicar o mesmo «liuro», «reuisto e emendado» ${ }^{1}$. O Flos Sanctorum de 1513 é, como se sabe, o representante português da tradição de traduçóes da Legenda Aurea, «nacionalizado» com adiçóes de santos portugueses ou com culto muito difundido em Portugal, a partir da tradução castelhana do ramo da chamada Compilação $\mathrm{B}$ de traduçôes do legendário latino ${ }^{2}$. Constitui um elo da cadeia de transmissão da hagiografia de tradição medieval divulgada nas legendae novae criadas pelos dominicanos a partir do séc. XIII e, especificamente, de tradição hispânica, na medida em que incorpora textos hispânicos ou que tiveram especial acolhimento em área hispânica. Foi, portanto, precisamente este corpus, medieval e hispânico com adiçôes portuguesas, que esteve sob a avaliação de Bartolomeu dos Mártires e do seu colaborador Diogo do Rosário, avaliação de que resultou um juízo condenatório por conter "algúas cousas muy incertas e apocriphas», carecendo, por isso, de emenda e revisão, e por ser lacunar, faltando-lhe «muitas vidas de sanctos que tee agora nam vieram a luz na nossa lingoa Portugues».

O conceito de apócrifo é, portanto, a pedra de toque da reforma do legendário e, nisto, concordante com os critérios de Trento. A duplicação redundante «incertas e apocriphas» esclarece o que está em causa. Apócrifo será aquilo que não pode ser tomado como certo, como verdadeiro; a falta de credibilidade decorre não tanto de uma qualidade intrínseca do objeto, verificável objetivamente, mas sobretudo da sua falta de validação por uma fonte autorizada. Está em causa a verdade histórica mas ela repousa essencialmente no reconhecimento da qualidade de quem a proclama. Os objetivos da reforma cumprem-se, portanto, com o anúncio de Fr. Diogo: «trabalhey quâto pude por lançar fora todo ho apocripho e duuidoso, e trazer diante hos lugares onde ho tirey». A certificação da verdade faz-se com a declaraçáo das fontes, garantia do «credito» dos textos, e depende de um consenso que aprova a qualidade dos autores. O princípio assim exposto tem um modelo inspirador, «Aloysio Lipomano bispo Ueronense».

1. No mesmo ano de 1513 imprimiu-se em Lisboa O Livro dos Mártires (Lisboa, João Pedro Bonhomini de Cremona, Biblioteca do Paço Ducal de Vila Viçosa, 36, BITAGAP manid 1028), tradução de parte da obra de Bernardo de Brihuega, mas a restrição do corpus aos mártires não admite que Fr. Diogo a identificasse com a sua Historia das vidas dos santos.

2. Sobre esta tradução e suas relações com o legendário português, v., por todos, a recente síntese de Aragüés Aldaz 2016. 
Luís Lippomano (1500-1559) era conhecido do clero português, depois da sua estadia em Portugal em 1542 como núncio apostólico, com a missão de convidar os bispos portugueses a participar no concílio que entáo se preparava. A sua obra mais conhecida é uma coleçấo hagiográfica impressa em oito volumes sob o título Sanctorum priscorum patrum vitae. O terceiro volume foi dedicado ao rei D. João III de Portugal, o que permite supor que a corte portuguesa terá sido contemplada com a oferta ao menos desse volume (se não também dos anteriores). A principal motivaçáo de Lippomano é vencer as críticas luteranas demonstrando a autenticidade do culto dos santos e, portanto, a sua legitimidade. A prova da autenticidade dos cultos faz-se demostrando a sua antiguidade e a antiguidade dos santos atesta-se com a antiguidade dos autores que sobre eles escrevem. Assim, é a finalidade apologética e contra-reformista que determina a estrutura e as características da compilação: o extenso corpus, formado entre os santos mais antigos, organiza-se por ordem cronológica e as fontes incluem o menológio de Simeão Metafraste e o martirológio de Adão de Viena, sendo a mais recente Bernardo de Claraval. Lippomano une à função apologética o objetivo de disponibilizar textos que podem servir para a instruçáo dos menos cientes, conferindo-lhes, pela escolha de autores aprovados e pela exclusão de apócrifos, a credibilidade que poderia eximir a hagiografia às suspeiçóes luteranas (Boesch-Gajano 1990: 119-121). A compilação, usada por hagiólogos posteriores como Lourenço Surio, mereceu deles muitas críticas. Desde logo, a extensão do corpus, que obviava à sua fácil utilização, e a ordenação cronológica quebravam o laço de familiaridade que tradicionalmente a leitura hagiográfica mantinha com os leigos e com a leitura privada. Além disso, a preocupação com a antiguidade e a limitação do critério de seleção das fontes deixara de fora os santos modernos e os santos "nacionais» ou "locais», excluindo assim aqueles que mais facilmente podiam suscitar sentimentos de viva religiosidade (Boesch-Gajano 1990: 125-6). Por fim, uma censura à coerência: apesar do anunciado rigor do critério de seleção das fontes, é o próprio compilador que o infringe, excluindo textos do aprovadíssimo Simeão Metafraste que lhe pareceram fabulosos ou risíveis (Boesch-Gajano 1990: 127). Estamos, portanto, perante uma concepçáo de autenticidade, de historicidade, fundada não apenas na aprovação das fontes mas também no exercício de um juízo a que hoje chamaríamos crítico e que opera, provavelmente, pelo confronto entre a narrativa e o conhecimento empírico do real. Equivale isto a dizer que uma concepção historicista e racionalista da matéria hagiográfica parece emergir para se sobrepor à concepção essencialmente mitográfica da Idade Média. Talvez seja, todavia, cedo ainda para que ela se manifeste consistentemente.

É este o mestre evocado por Fr. Diogo e, por isso, são estes os princípios cuja aplicação podemos esperar. Porém, é muito provável que o frade português tenha em mente não os oito volumes das Sanctorum priscorum patrum vitae mas sim uma antologia que delas se fez em 1565, com o título Historiae Aloysii Lipomani, episcopi veronensis de vitis sanctorum. Desta síntese existe hoje um 
exemplar na Biblioteca Nacional de Lisboa, proveniente de um Colégio regular de Coimbra, o que atesta a sua divulgação em Portugal. É difícil não notar que a antologia, em dois volumes tal como o legendário de Diogo do Rosário, se lhe assemelha também no título (Historiae... vitis sanctorum / Historia das vidas... dos sanctos). A dedicatória ao leitor esclarece que se pretende, sem descurar a importância da autoridade das fontes, preocupação magna de Lippomano, extrair dos oito volumes as vidas dos santos notáveis e especialmente as daqueles cujas festas são célebres, trazendo de novo à leitura comum santos familiares. Trata-se, portanto, de extrair da obra de Lippomano um verdadeiro legendário, devolvendo-lhe a portabilidade e recuperando o espírito da seleção dos melhores, as Flores Sanctorum medievais.

É neste enquadramento que surge o legendário de 1567 . Resistindo à tentaçáo de juntar mais vidas de santos do que recomendava a facilidade de utilizaçáo, continuando a tradição medieval de antologias portáteis, cujos textos são ordenados segundo o calendário litúrgico, de forma a ocupar um espaço cativo na vida quotidiana dos que sabem e podem ler, Fr. Diogo do Rosário propóe-se rever e emendar a tradiçáo, soprando-lhe os ventos reformadores do método bebido em Luís Lippomano e da orientação tridentina do seu patrono Bartolomeu dos Mártires. O público-alvo não são apenas os que buscam matéria predicável mas todos aqueles que tradicionalmente leem o Flos Sanctorum, e que agora devem reformar o seu "gosto» com o «credito» assegurado pelas auctoritates.

\section{O corpus do legendário (Ajuntey... muitas vidas de sanctos... e muitas tambem deixey de traduzir)}

Como se operou a revisão e quais foram os seus resultados práticos? Em que se distingue o corpus aprovado em 1567 daquele que se lia impresso desde o início do século e manuscrito no anterior? As respostas só podem cabalmente resultar de um estudo aprofundado do legendário. Analisarei aqui alguns aspetos que podem constituir um primeiro contributo.

Importa conhecer, em primeiro lugar, o grau de inovaçáo da lista de santos, comparando-a com a lista de santos do Flos Sanctorum de 1513. Esta lista, por sua vez, deve ser considerada como o resultado de uma operaçáo semelhante de seleçáo de corpus feita sobre o modelo castelhano traduzido e que podemos avaliar através do incunábulo que atualmente melhor o representa, a Leyenda de los Santos (British Library IB.53312; BETA manid 2243; Aragüés Aldaz 2016). A comparação dos corpora dos três legendários permite pôr em evidência as coincidências ${ }^{3}$.

3. Porque é a concepção da santidade histórica que propriamente quero indagar, considerei apenas textos relativos a santos, festas e santuários marianos e não as festas do temporal, nem textos de exposição litúrgica ou doutrinária. 
A redução do corpus que Trento preconizara para a reforma do breviário não se aplica às coleçôes hagiográficas, que não têm função litúrgica. Pelo contrário, a sua função apologética e a sua direção para a leitura privada e para a pregaçáo estimulam a ampliação do corpus, dentro dos limites de portabilidade do livro. Não surpreende, por isso, que, dos três legendários, a Historia das vidas dos santos $(\mathrm{H})$ seja o que apresenta maior extensão de texto: totaliza 494 fólios, que, comparados com os 306 da Leyenda de los Santos (B) e, sobretudo, com os 265 do Flos Sanctorum de 1513 (F), parecem apontar para uma duplicação do texto. Haverá que considerar nesta diferença causas tipográficas ${ }^{4}$, as quais, porém, não justificam inteiramente a dissemelhança: B tem 188 textos hagiográficos, ligeiramente reduzidos em F para 184; H inclui 223 textos. Destes, 62 são textos que não tinham sido incluídos em nenhum dos legendários medievais. Isto significa que apenas $27,8 \%$ do seu corpus hagiográfico é inteiramente novo, enquanto $72,19 \%$ é partilhado com os legendários hispânicos medievais. A maioria dos textos, 121 (54,26\%), pertence à tradição comum da Legenda Aurea 5 . Com o legendário que pretende substituir, F, a Historia partilha 153 santos e festas $(68,6 \%)$.

Do fundo de 137 textos que tanto B como F mantêm em comum com a Legenda Aurea, apenas 16 dos textos que tinham sido consensuais para $\mathrm{B}$ e $\mathrm{F}$ não são acolhidos por H: Dois irmãos Felizes, Amando, Eusébio, Germano, João eremita, João posto na tina, Pedro de Coroa de Grados, Leão, Pelágio, Quatro Coroados, Quintino, Quirce e Julita, Saturnino e outros, Teodora, Tiago Interciso, Virgem de Antioquia. Destes textos, a exclusão da passio de Quirce e Julita explica-se no facto de ter sido condenada como apócrifa no Decreto Gelasiano (Dobschütz I9I2: I3; De Gaiffier 1964; Mimouni 20 I I: 247-256). Diogo do Rosário conhecia a condenação da passio de S. Jorge, tal como declara na didascália que a introduz no seu legendário:

Historia da vida e martyrio do béauenturado sam Jorge, segundo a escreue Simeon Metaphrastes: A qual he autentica e náo apocripha, nem he aquella que por apocripha julgou o papa Gelasio, dist.xv. sancta Romana ecclesia, como manifesta Aloysio Lipomagno bispo de Uerona. (Primeira Parte, 212v)

E não desconhecia a condenação de Quirce e Julita, através da sua fonte principal, S. Antonino de Florença (Historiarum, edição de $1527^{6}$, I, 165): "Quirici et Julite matris eius quia inter apocryphas ponitur»).

4. Em ambos textos a duas colunas, em F com 49 linhas e uma média de 42 caracteres por linha, em B com 47 linhas e uma média de 36 caracteres por linha.

5. Refiro o corpus tal como o estabelece G.P. Maggioni (Iacopo da Varazze, Legenda Aurea).

6. As Historiarum sive Chronicon partibus tribus distincta ab initio mundi ad MCCCLX foram publicadas pela primeira vez em Veneza, em 1474-79, com mais oito reimpressóes até 1587. 
As restantes festas excluídas dizem todas respeito a santos antigos, entre mártires, eremitas, monges, bispos e festas secundárias de evangelistas. Não há um critério evidente que explique todas estas exclusões, até porque para alguns destes textos havia notícia em Lippomano ${ }^{7}$. $\mathrm{O}$ critério de antiguidade não é aceitável, visto que muitos outros santos coevos são acolhidos no legendário. É provável que se tenha tratado simplesmente de eliminar textos do mesmo tipo de outros acolhidos, criando assim espaço para os textos completamente novos. Poderíamos, por exemplo, questionar a exclusão de Tiago Interciso, que era festejado na igreja de Braga com festa dúplice desde que, em 1117, o arcebispo D. Maurício Burdino (1109-1118) nela depositara as relíquias do mártir persa trazidas da Terra Santa. No entanto, considerando os novos santos bracarenses que virá a integrar, como veremos, é provável que um mártir com pouca atenção nas devoçôes populares tenha caído para dar lugar a outros.

Como é sabido, em B encontram-se várias adiçôes feitas à Legenda Aurea na sua traduçáo em castelhano, quer em apêndice final (Santos Extravagantes) quer em interpolaçóes no núcleo central do legendário. São, na sua maioria, textos sobre santos hispânicos. Destas adiçóes, a tradução portuguesa conserva 29, das quais $\mathrm{H}$ acolhe 16 e rejeita 13. Porém, o seu acervo de santos hispânicos não é pequeno porque recupera 8 dos textos que F eliminara: Eulália de Mérida, Isidoro de Sevilha, Justa e Rufina, Leandro de Sevilha, Leocádia de Toledo, festa de Santa Maria do O, Tomás de Aquino, Eufrosina. Se compararmos esta lista com os 13 santos acolhidos por $\mathrm{F}$ mas não por $\mathrm{H}$, talvez possamos entrever o critério que presidiu à seleção: Amaro, Antolim, Atilano, Eulália de Barcelona, Facundo e Primitivo, Heleno, Quitéria, Susana virgem e mártir, Patrício de França, Toríbio de Astorga, trasladaçáo de Santo Ildefonso, Um imperador de Roma e sua mulher Beatriz, Victores de Cerezo. Entram no corpus de $\mathrm{H}$ santos históricos como Isidoro e Leandro de Sevilha e Tomás de Aquino, mártires de culto muito cedo atestado, como Justa e Rufina e Eulália de Mérida. Estáo ausentes outros, cujas vidas, essencialmente literárias e romanescas, poderiam ser consideradas duvidosas, como Amaro, Beatriz e Quitéria, ou mártires de culto mais tardio ou menos firmemente atestado, como Eulália de Barcelona e Susana. Já a presença de Eufrosina mas não de Heleno, ambos transmitidos nas Vitae Patrum que se divulgaram na Península Ibérica, integrados, por exemplo, na Compilação de Valério de Bierzo, só pode explicar-se pelo facto de o caráter romanesco e exótico da santa travestida ocupar tradicionalmente um lugar cativo na curiosidade do público. Certo parece ser o não acolhimento de trasladaçóes. Quer tenham sido acrescentadas pela Leyenda (Ildefonso, Eugénio e Isidoro) quer pelo Flos Sanctorum (Vicente), não merecem o interesse de Diogo do Rosário. Ausentes estão também santos como Fernando de Castela, Florentina, Fulgêncio, Bráulio de Saragoça, Laureano de Sevilha, Santa Maria do Pilar, Servando e Germano, Severi-

7. Por exemplo, na Segunda Parte estão os Quatro Coroados (160) e os milagres de S. Quintino (163). 
no de Tolosa ou Valério de Saragoça, os quais podem ser considerados de segunda linha quanto ao seu conhecimento e sua difusão em Portugal.

Diogo do Rosário comporta-se, aparentemente, como o compilador do Flos Sanctorum, assumindo em parte muito considerável o corpus hagiográfico hispânico. A seleção que opera nesse corpus é, em parte, comum à dos legendários medievais, até no critério de atualização que consiste em dar preferência a santos mais divulgados e significativos para o seu público. Aparentemente diferencia-se dele dando validade plena a uma condenação tida como pontifical mas à qual a Idade Média se mostrou indiferente. De facto, as legendas fabulosas cuja condenação se atribuía ao papa Gelásio foram acolhidas por muitos hagiógrafos medievais e, entre eles, por Jacopo de Varazze. O reformado espírito historicista de Diogo do Rosário parece, portanto, assentar num critério de autoridade herdado da Idade Média. Que neste caso a Idade Média não o tenha respeitado e que o Decreto do papa Gelásio não tenha sido escrito pelo papa Gelásio, constituindo, portanto, ele próprio, um apócrifo, são ironias pré e pós-tridentinas.

Quanto às adições feitas por $\mathrm{F}$, todas de textos sobre santos portugueses ou com culto em Portugal, apenas dois textos sáo excluídos: a já mencionada trasladação de S. Vicente do Algarve para Lisboa e o remoto S. Goldofre, cuja vida é totalmente literária e que teve sempre um culto muito limitado, local e já decadente no séc. XVI (Sobral 2000: 481). A Historia supre algumas das lacunas que surpreendem no corpus de F: não encontramos explicação satisfatória para, em 1513, ter-se omitido santos portugueses cujo culto estava entáo vivo, santos como Martinho de Braga, Teotónio de Coimbra, os Mártires de Marrocos ou a Rainha Santa Isabel. Constatamos, porém, que, em 1567, entre os textos comuns a $\mathrm{F}$ e os incluídos de novo, Fr. Diogo reúne um pequeno santoral português: António de Lisboa, Dâmaso papa, Frutuoso de Braga, Geraldo de Braga, Gonçalo de Amarante, Iria, Isabel de Portugal, Mártires de Marrocos, Martinho de Braga, Pedro de Rates, Teotónio, Tirso, Torcato, Veríssimo e suas irmãs Máxima e Júlia, Vicente e suas irmãs Sabina e Cristeta, Vítor de Braga.

Conclui-se, portanto, que Diogo do Rosário não aliena a tradição hagiográfica medieval, nem na sua dimensão europeia representada pela Legenda Aurea, nem na sua dimensão hispânica representada pela Leyenda de los Santos, nem tão pouco na sua dimensão «nacionalizante» expressa pelo Flos Sanctorum de 1513, cujo corpus nacional reforça e no qual integra tanto mártires da perseguição de Diocleciano como modelos de santidade moderna (Rainha Santa Isabel). Afasta-se, nisto, do seu mestre Lippomano.

\section{A revisão do legendário (trabalhey quãto pude por lançar fora todo ho apocripho e duuidoso...)}

Para avaliar em que medida a Historia das vidas dos Santos se afasta do Flos Sanctorum medieval, um dos pontos de observação mais interessantes são os santos comuns a ambas as obras, visto que, para estes santos, Fr. Diogo do Rosário 
dispunha de um texto facilmente acessível, o qual poderia, se assim o entendesse, limitar-se a refrescar linguistica ou retoricamente. Como uma das novidades deste legendário é a declaração das fontes, podemos sem dificuldade saber se assim aconteceu. Vejamos quatro casos.

A vida do dominicano S. Gonçalo de Amarante (Primeira Parte, fls. 61v66) conta-a Fr. Diogo, alegadamente, «segundo estaa escripta no moesteyro do dito sancto em Amarante, e a escreueo o doctissimo mestre frey Andre de resẽde no officio q̃ cópos do dito sancto» (Primeira Parte, 61v). A colação de todas as legendas gonçalinas conhecidas e anteriores a 1567 confirmou que, de facto, o ofício litúrgico composto pelo humanista André de Resende (Resende 1562/63) foi uma das fontes utilizadas, literalmente traduzido em vários passos, inclusive em liçóes características suas, resultantes de interpolação (Sobral 2000: 169-83, 180-1). Porém, esta fonte é apenas de recurso pontual. Quanto ao que fosse a vida do santo que estava no mosteiro de Amarante, nada é claro. O que sabemos é que o texto de Diogo do Rosário segue de muito perto uma compilação hagiográfica dominicana de 1552 , na qual o texto relativo a $S$. Gonçalo tem o seguinte incipit: "Começa a vida de sam Gonçalo de Amarăte como se escreue em ho liuro das vidas dos sanctos que comũmente se chama Flosantorum» (São Domingos 1552: 117; Sobral 2000: 181-2). Por seu lado, este texto é táo próximo do texto do Flos Sanctorum de 1513 que certamente dele depende, se não direta, ao menos indiretamente. A evocada vida de S. Gonçalo que estava em Amarante podia bem ser uma cópia ligeiramente refundida do texto de 1513, o mesmo que ficara sob a condenação geral lançada ao legendário por Fr. Diogo, o qual, porém, náo omite nenhum dos milagres de F. Podemos mesmo dizer mais: tendo o ofício de Resende omitido os mais espetaculares desses milagres ${ }^{8}$, e tendo Fr. Diogo usado essa fonte, não a considera suficiente e prefere "completar» o texto com outra, mais extensa e narrativamente mais complexa, comportando-se como um compilador medieval, que selecciona sempre em favor da abundância (Sobral 2000: 181), e indo ao encontro do texto de 1513, que rejeitara.

A passio de S. Manços de Évora (Primeira Parte, fls. 256-275), mártir do séc. VI, escrita talvez por um monge da região (Fernandez Catón 1983: 184), provavelmente no final do séc. vII ou início do VIII com recurso a tradiçóes orais e talvez refundida no séc. XI, conta a história de um servo romano que acompanha até à Península Ibérica uma família ou grupo de judeus, que se fixaram na regiáo de Évora (BHL 5219). Forçado a praticar o culto judaico, recusa-se confessando a fé cristá, é castigado e sujeito a trabalhos forçados, que o levam à morte. No séc. XIV, os breviários beneditinos levam Manços até à Palestina e fazem-no participante no ciclo da Paixão e na primeira metade do séc. XVI transformam-no no primeiro

8. O vinho jorra de uma rocha e o peixe do rio oferece-se para alimentar os operários que constroem a ponte de Amarante; pedras enormes são facilmente movidas; pães são transformados em carvôes para explicar o efeito da excomunhão. 
bispo de Évora, fundador desta igreja e mártir da primeira perseguição romana (Fernandez Catón 1983: 135). É essa a versão de F, traduzida de B, onde constitui uma das adições do núcleo central, a partir das liçóes dos livros litúrgicos beneditinos dos séculos XIV-XVI (Fernandez Catón 1983: 193-196), com adiçóes que amplificam a narrativa e introduzem motivos hagiográficos comuns, como o da alma do mártir que se eleva em forma de pomba. Em Évora, logo no Missal de 1509 (Missale... Elborensis Ecclesie; Oliveira 1962/63: 267-8, Díaz y Díaz 1993: 176), Manços aparece, no calendário, festejado com festa dúplice e associado à fundação da igreja («Mancij elborẽsis martyris duplex. hac die fuit fundata ecclesia elborensis»), associação que se repete nos breviários de 1528 (Breuiarium... Elborensis ecclesie; Oliveira 1962/63: 268-9, Díaz y Díaz 1993: 173) e de 1548 (Breuiarium Eborense; Oliveira 1962/63: 269-71). Estes dois breviários apresentam lições diferentes. No primeiro falta a referência à elevação da alma em forma de pomba e a parte final que conta a invenção e a trasladação das relíquias. O Breviário de 1548 foi composto, como é sabido, por André de Resende (De Gaiffier 1942, Oliveira 1962/63: 270), o qual refunde o texto, atualizando a redação e integrando os elementos que faltavam no breviário anterior.

É o Breviário de Évora a fonte alegada por Diogo do Rosário: «Historia do martyrio de sam Mancio discipolo de Christo segundo o breuario Deuora.» (256b). E, de facto, a sua história de S. Manços é tradução literal das liçóes de Resende. O Breviário de Braga de 1549 (Breniarium bracharense, Ferreira 1924: 173, Díaz y Díaz 1993: 172) também inclui o ofício de S. Manços, na versão de Resende, copiada do de Évora com variantes gráficas, sem a introdução relativa à cidade e sem a invençáo nem a trasladaçáo finais. Apesar de, noutros textos, ambos os breviários serem evocados como fonte (v. adiante Pedro de Rates), desta vez Fr. Diogo declara apenas aquele que terá efetivamente usado. O que é significativo é o seu critério de seleção: trabalhando para o Arcebispo de Braga, prefere o Breviário de Évora, que é a fonte mais completa, com maior número de elementos narrativos. Relativamente a F, que continha uma versão com os mesmos elementos das liçóes de Resende mas sem trasladação e com a invenção reduzida a duas frases muito simples, é notória a preferência pela versão mais "completa» e mais maravilhosa.

Santa Apolónia (Primeira Parte, fls. 123r-123v) não pertence ao corpus da Legenda Aurea mas foi-lhe acrescentada em mais do que uma edição. A de Graesse (1850), baseada numa das primeiras impressóes do legendário, inclui-a na versão BHL 0630, que é a passio histórica extraída de Eusébio de Cesareia (Historia Ecclesiastica, I, 6. 41), o que significa que estava disponível para a leitura hagiográfica, na segunda metade do séc. Xv, uma legenda histórica, que contava o martírio de uma virgem de Alexandria, de idade avançada, em 248-249, cujo principal tormento fora a extração de todos os dentes.

$\mathrm{B}$ acrescenta-a nos Extravagantes (com tradução fiel em $\mathrm{F}$ ) recorrendo à tradiçáo das legendas BHL 0641, que têm diversas variantes (a BHL regista três). Esta tradição, que se estabelece a partir do séc. XIv, é totalmente lendária. Conta a história de uma jovem filha de um rei pagáo que se converte miraculosamente 
graças a revelações e à intervenção de um eremita. Em comum com o texto histórico há apenas o tormento dos dentes, que identifica a mártir na iconografia e que fundamenta a proteção contra as dores de dentes para que é invocada.

Diogo do Rosário não acolheu a legenda de que dispunha no Flos Sanctorum. Preferiu outras fontes: «segundo o breuiario de Euora, e segúdo Eusebio Cesariense, que conta somentes o seu martyrio, liuro oitauo da historia ecclesiastica». Posto em paralelo com a fonte histórica, é de novo sobre o ofício do Breviário de Resende que repousa o crédito da legenda da Historia. Considerando, porém, que a declaração sobre as fontes supóe que há mais para contar do que apenas o martírio contado por Eusébio, pergunta-se de onde virá o resto.

A narrativa de Resende, de facto, parece histórica, visto que não tem maravilhoso, nem sequer milagres post-mortem ou sinais de glorificação. Mas contém mais do que a Historia Ecclesiastica. Já os bolandistas haviam notado (AASS, Fevereiro II: 279) que o Breviário de Évora de 1548 apresenta uma versão que cola a narrativa de Eusébio com a passio de Eulália de Mérida. De facto, a colagem é tão flagrante que, apesar de dizer, na primeira lição, que Apolónia chegara a idade avançada ( aad maturam peruenit aetatem»), náo hesita colocar na boca do juiz (sétima lição) uma apreciação da sua formosura («nobilitati \& pulchritudini tuae»). É claro que, na época, nem os padróes estéticos nem os artifícios da maquilhagem feminina permitiam ainda conciliar idade avançada com formosura. E o que faz Diogo do Rosário perante esta incoerência? Não só não a deteta como a acentua. Traduzindo literalmente todo o texto de Resende, faz apenas uma interpolação, precisamente para, alegando a fonte histórica, acentuar a idade da heroína: «Apollonia sendo ja molher anciaã (segưdo diz Eusebio) desejando de morrer polo nome de Jesu Christo, se sayo de casa a mea noyte...». Chegando ao diálogo com o juiz, lá está a formosura da anciá Apolónia: «tee qui ouue doo e compaixam de tua fidalguia e fremosura...».

Tanto o humanista eborense como o fiel seguidor de Fr. Bartolomeu dos Mártires transmitem, portanto, uma paixão de Santa Apolónia notoriamente apócrifa, ainda que baseada em elementos históricos e sem o maravilhoso que caracteriza o final da passio da mártir emeritense. A censura deve recair sobretudo sobre o humanista, pois é dele a autoria do pastiche, cabendo a Diogo do Rosário apenas a culpa da falta de espírito crítico e a cega confiança depositada no Breviário.

A Vida de Santo Ildefonso (Primeira Parte, $86 \mathrm{v}-87 \mathrm{v}$ ) é uma das mais surpreendentes no que se refere a fontes, visto que é a única que cita o Flos Sanctorum: «Historia da vida de sã́cto Jllefonso Arcebispo de Toledo, segúdo se escreue no flos sanctorum, abreuiada, e no breuiario de Euora» (86v).

Em F é um dos textos mais extensos (32v-39r) e traduz literalmente B, que apresenta uma versáo prosificada a partir da Vida de Sant Alifonso por metros, do Beneficiado de Úbeda. O resultado é uma versão muito prolixa, com longas falas em discurso direto, que não observou o princípio da abbreviatio. Em contrapartida, as nove lições do Breviário de Évora de 1548 são mais abreviadas do que gostaria o nosso compilador. $\mathrm{O}$ crédito que lhe merece esta fonte determina, 
todavia, que, mesmo assim, seja a escolhida, havendo apenas que completá-la com elementos provenientes de fonte mais extensa.

$\mathrm{O}$ texto de Resende esquematiza drasticamente a biografia de Ildefonso: nada diz de seus pais a não ser a sua nobreza, nem da profecia da Virgem. Reduz o percurso de aprendizagem do santo a poucas linhas e resume numa mesma frase a sua nomeação para arcediago e a sua eleição para o abaciado de $S$. Cosme. Detém-se um pouco mais na narração das circunstâncias em que foi escrito o livro sobre a virgindade de Maria e repóe a verdade histórica acerca da participação de Ildefonso no X Concílio de Toledo e na instituição da festa de Nossa Senhora do $\mathrm{O}$ a 18 de Dezembro, atribuindo essas iniciativas ao seu antecessor Eugénio. Omite todos os elementos de maravilhoso, exceto o milagre da doação da casula, que conta detidamente ao longo de três liçóes e onde inclui a referência ao sucessor, Sigiberto, castigado com a destituição do cargo e a expulsão do arcebispado. Segue-se a morte do santo e a sua inumação na igreja de Santa Leocádia. Aparentemente, o milagre da doação da casula é considerado mais credível que os restantes, havendo talvez nisto que considerar o efeito da singularidade. A enumeração de milagres - na legenda medieval duas apariçóes da Virgem e uma de Santa Leocádia - pode resultar em banalização, retirando-lhe o crédito que resulta de uma singularidade excepcional.

Esta é a fonte que Fr. Diogo traduz literalmente, seguindo-a na versão histórica do Concílio e da instituição da festa e no castigo humano e realista do sucessor que ousou sentar-se na cadeira. Porém, fazia falta mais alguma matéria para transformar esta história em leitura agradável. Para isso, recorre a uma fonte alternativa, com a qual interpola a tradução do breviário. São dois os temas que merecem a sua atenção. Desde logo, a descrição dos costumes e das virtudes do santo, primeiro enquanto educando de Santo Eugénio, depois enquanto abade e finalmente como arcebispo. No ciclo da entrada para o mosteiro, acrescenta as motivaçóes do santo, que teme os "perigos da honra e do mundo». Na eleição para o arcebispado, enquanto as lições do Breviário se centram no facto de ela ter sido divinamente inspirada ao povo, Fr. Diogo evita o tema, que fora objeto da $22^{a}$ sessão de Trento, em que se definiu o apertado escrutínio a que os elegíveis a bispo ficam, a partir de então, sujeitos. Prefere sublinhar a utilização, na cura pastoral, da ciência previamente adquirida, mais uma vez em consonância com Trento, que exigia (cap. II, da 22a sessão) que os futuros bispos estivessem instruídos de modo a poderem desempenhar cabalmente as suas funçóes. Parece evidente que Fr. Diogo não quis perder a oportunidade de mostrar em Santo Ildefonso um modelo de homem religioso, precoce já na infância, mas sobretudo exemplar enquanto prelado pós-tridentino.

O segundo tema objeto de refundição é o maravilhoso. Devolvendo à legenda alguns dos seus elementos medievais, Fr. Diogo recupera a primeira aparição da Virgem, em agradecimento pela escrita do livro sobre a sua virgindade. Recupera igualmente o sinal de glorificação constituído pela alvura do cadáver e os milagres post-mortem, genericamente designados. Por fim, não deixa de incluir o 
castigo do sucessor que ousou vestir a casula oferecida pela Virgem mas, por coerência com o que antes dissera, traduzindo o Breviário, acerca de Sigiberto, que ousara sentar-se na cadeira, também nesta segunda entrada em cena do sucessor não há milagre castigador e sim apenas a deposição e a expulsão. Não cede, portanto, Fr. Diogo a todo o maravilhoso da legenda medieval. Confrontado com o espírito mais realista de Resende e mais milagroso da sua outra fonte, opta pelo primeiro sem deixar de dar conta da versão alternativa: «O qual por sua soberba e doudice foy lançado fora da dignidade e cadeira Episcopal, e no degredo acabou sua triste e misera vida (Inda que outros digam que vestindoa logo morreo)».

De onde provêm estes elementos? Pareceria óbvio o recurso ao Flos Sanctorum de 1513, que contém todos os elementos medievais recuperados, se não fosse o caso de em nenhum deles termos evidência de importação textual. Coincide a matéria mas não a redação. Há duas hipóteses que podem explicá-lo: ou Fr. Diogo usou, de facto, F, refundindo sempre a redação e não apenas abreviando, como anuncia, ou o "flos sanctorum» que alega não é o de 1513. Não há referência à língua deste "flos sanctorum», o que sugere que ele poderia ser em latim (com este santo adicionado, visto que ele náo faz parte do corpus da Legenda Aurea). Mas nada obsta a que a refundição tenha sido feita a partir de F. De resto, a adiçáo de certos elementos históricos que náo estáo nem no Breviário nem em F, como os livros escritos por Ildefonso, o dia da morte e o reinado em que ocorreu, podem indicar iniciativa própria.

Neste caso, mesmo que a fonte alternativa tenha sido F, o seu uso obedeceu em parte ao critério de expurgo de apócrifo, sem deixar de entregar-se à fonte de autoridade mais forte, o Breviário de Resende, a decisão acerca do que assim deve ser considerado, rejeitando a maior parte dos milagres que ele rejeitou. Não hesitou, no entanto, o compilador, em recuperar elementos maravilhosos, destacadamente os da glorificaçáo do santo, que são estruturais na construção de uma narrativa hagiográfica. Existem ainda indícios de ter sido consultado outro breviário: a metáfora da fonte que caracteriza a transferência de saber de S. Isidoro para S. Ildefonso só se encontra no Breviário de Braga de 1494, lectio 3, 194v:

Non impar meritis sanctissimi illius isydori. de cuius fonte adhuc clientulus. latices purissimos hausit: quibus postea totam hispaniam ut prudens et fidelis seruus irrigauit.

(...) se prẽdeu e atou acerca do sanctissimo varáo s. Jsidoro, e com tamanho desejo se pegou aa sua doutrina que em pouco tempo tirou de sua fonte, o que depois fielmente derramou no pouo christão. (Historia, Primeira Parte, 86d)

Porque não mereceu referência este breviário? Talvez porque o facto de ser anterior e, portanto, independente do de Resende, o qualificasse menos aos olhos de Diogo do Rosário.

Vale a pena ainda observar o comportamento do compilador face a santos incluídos de novo, como S. Pedro de Rates (Primeira Parte, 219). Trata-se de 
um dos falsos arcebispos de Braga, o primeiro a figurar numa longa lista que não parou de aumentar a partir do séc. XVI, sobretudo depois da publicação dos falsos cronicóes, que forneceram uma galeria de novos santos a autores posteriores (Ferreira 1924: II, 209-10, 228-32). Nasce este mártir no séc. XVI, de origens obscuras: surge no Breviário de Braga de 1511 (Salamanca, João de Porres; Ferreira 1924: 2, 282, Díaz y Díaz 1993: 172), celebrado a 26 de Abril, como um dos discípulos de S. Tiago, com ele vindo à Hispânia, onde é sagrado bispo de Braga, fundando assim esta igreja em época apostólica. A narrativa filia-se na tradição medieval das lendas dos varóes apostólicos e pode ter sido motivada pela procura de fundamentos para a causa bracarense na disputa com Toledo pela primazia da Igreja peninsular. O ofício repete-se no Breviário de 1528. No de 1548 , surge, entretanto, pela mão de Resende, uma nova versão do mesmo texto que conserva todos os seus elementos narrativos exceto os milagres, mas que refunde a redação, amplificando-a ligeiramente. No Breviário de Braga de 1549, é esta nova versão, que deve atribuir-se, sem dúvida, a Resende, que é adotada, mantendo-se, na $3^{a}$ lição, os milagres que já constavam na edição de 1511 do Breviário.

Em 17 de outubro de 1552, o arcebispo D. Baltasar Limpo (1550-1558) manda trasladar o corpo para a Sé de Braga, fundando e dotando aí uma capela dedicada ao ignoto arcebispo (Castro 2000: 191). A invenção das relíquias segue padróes comuns a estes casos. Havendo na igreja românica de Rates um túmulo sem qualquer inscrição, fez-se a simples correspondência entre estes restos mortais e o santo arcebispo, menosprezando o facto de as dimensóes da urna indicarem que se trataria dos restos mortais de uma criança (Oliveira 1964: 104). Em 1578, o papa Gregório XIII concedeu a Fr. Bartolomeu dos Mártires uma indulgência num altar da Sé de Braga à sua escolha e ele escolheu o altar de S. Pedro de Rates (Castro 2000: 192), consolidando e popularizando assim o novo culto.

A legenda é totalmente fabulosa. O discípulo de $S$. Tiago cura da lepra a filha do rei local e converte-a, juntamente com a rainha sua mãe. Convence ambas a manterem castidade, o que enfurece o rei pagáo, que manda matar o arcebispo. Este foge para Rates, onde é intercetado e morto pelos esbirros do rei. Os moradores receiam a fúria do monarca e deixam o corpo insepulto mas, recebendo uma revelação, o eremita Félix vem sepultá-lo, dando origem a um local de peregrinação. Diogo do Rosário traduz literalmente o ofício do Breviário Bracarense de 1549, incluindo os milagres póstumos da terceira lição, com excepção apenas do último, que substitui pela referência à trasladação de 1552.

Toda a credibilidade da narrativa assenta, assim, no testemunho do livro litúrgico e é evidente que o sancionamento do culto por dois arcebispos recentes dá uma nota final e conclusiva a essa credibilidade. Apesar de Diogo do Rosário conhecer o Breviário de 1494, que por vezes usa sem o declarar, não lhe ocorreu perguntar-se porque náo contém este breviário qualquer menção ao mártir nem que fontes o sustentam nos breviários seguintes, onde surge como num processo de geração espontânea. 


\section{Os doutíssimos varóes (trazer diante hos lugares de onde o tirei...)}

Uma das estratégias de credibilização em que aposta Fr. Diogo é, na esteira de Lippomano, a declaraçáo de fontes. Nas vernaculizaçóes medievais da Legenda Aurea falta tal declaração mas agora ela contribuirá para marcar a diferença, para discernir os textos apócrifos dos autorizados. Assim vimos suceder na substituição, com Lippomano, da versão romanesca e mitográfica da Vida de S. Jorge pela de Simeão Metafraste. Vimos também que a declaração de fontes nem sempre é exata. Ainda assim, dá-nos uma ideia geral do elenco de textos que foi usado. Antonino de Florença (1389-1459) é o preferido, com 112 atribuições de textos, seguido a larga distância por Cláudio de Rota ${ }^{9}$, com 23. Em terceiro lugar ficam, ex-aequo, Pedro de Natalis (c.1330-1406) ${ }^{10}$ e o Breviário de Évora (André de Resende) com 18 atribuiçóes cada. Porém, se somarmos todos os breviários usados (Braga oito atribuições, Santa Cruz de Coimbra três, Breviários Romano e Dominicano duas cada um e o Beneditino uma), facilmente constatamos que este tipo de fonte é uma das preferidas, totalizando 34 atribuiçôes de textos e roubando o segundo lugar a Cláudio de Rota ${ }^{11}$.

Estes dados dão-nos uma imagem do conceito de apócrifo que está em causa e da tensão que se vive, à saída de Trento, entre tradição e historicidade. Por um lado, a opção por versóes narrativamente mais elaboradas e complexas, a aceitação do maravilhoso e a prática da compilaçáo de fontes nem sempre declaradas com rigor evidencia a continuidade da tradição hagiográfica medieval e revela a função mitográfica das devoçóes aos santos. Por outro, e simultaneamente, há uma tentativa de conter esse maravilhoso medieval, evitando alguns dos seus elementos mais espetaculares (S. Ildefonso), muito embora esta tentativa não seja consistente, fraquejando nalguns casos ( $\mathrm{S}$. Gonçalo) e resultando os textos em versôes que não se distinguem substancialmente daquelas que anunciavam substituir.

Todas estas inconsistências parecem diluir-se sob o manto protetor de autoridades recentes, como Luís Lippomano e Cláudio de Rota, este último conhecido pela ação corretora que alega ter exercido sobre o legendário de Jacopo de Varazze ${ }^{12}$.

9. De Cláudio de Rota pouco ou nada se sabe, além de que era dominicano, professor de Teologia no convento de Lyon, e que preparou, sob o título Opus aureum et legende insignes sanctorum sanctarumque cum Hystoria lombardica, edições da Legenda Aurea de Jacopo de Varazze desde 1519 (Lyon, Guillaume Huyon) até 1554 (Lyon, Jean François de Gabiano), mediadas por impressóes em 1521, 1524, 1526, 1531, com adição de novos textos.

10. Do seu Catalogus sanctorum et gestorum eorum ex diversis voluminibus collectus conhecemos ediçôes de 1493 (Vicenza, Henricus de Sancto Ursio) até 1545 (Lyon, Jacques Giunta).

11. Vale a pena referir ainda seis atribuiçóes ao Martirológio de Adão (dito bispo de Trèves mas na verdade de Viena), outras tantas ao Speculum Historiale de Vicente de Beauvais e às Vitae Patrum, cinco a Simeão Metafraste (mediatizado por Lippomano) e três a S. Jerónimo (Epistola a Eustóquio e De viri illustribus). Além destas, há ainda uma longa lista de fontes citadas apenas uma vez.

12. Na página de rosto da ediçáo de 1554 da Legenda editada por Cláudio de Rota, anuncia-se: "Nunc demum summa cura diligentiáque Fr. Claudij à Rota, sacrae Theologiae professoris, ordi- 
Menos recentes são Pedro de Natalis e Antonino de Florença mas neste último pôde Fr. Diogo encontrar um filtro crítico que o credibilizava: S. Antonino compila a passio de S. Jorge considerada histórica e não a apócrifa, inclui Quirce e Julita e até mesmo Tecla mas sem deixar de alertar para o facto de ambos os textos constarem entre os apócrifos, o que terá levado Fr. Diogo a não os incluir e a usar os restantes com confiança. Ao contrário do que fez Lippomano, que procurou as fontes mais antigas que pôde encontrar para atestar a autenticidade dos textos, Fr. Diogo confia em autores que possam ter feito esse trabalho por ele. É sobretudo, portanto, o crivo destes autores e o seu prestígio reformador, nalguns casos imerecido ${ }^{13}$, que serve de elemento credibilizante e que sanciona o conteúdo das narrativas. Trata-se, provavelmente, mais de uma inevitabilidade do que de uma opção clara, visto que Fr. Diogo não teria acesso a fontes de primeira mão para todos os santos que compendia. $\mathrm{O}$ peso do Breviário de Évora não é alheio a este critério. Fr. Diogo sabia quem o compusera (Historia, Primeira Parte, 257a) e inclui Resende no grupo dos insignes varóes cujo espírito historicista e reformador (também imerecido, como sublinhou De Gaiffier 1942), lhe assegura a autenticidade dos textos. Por outro lado, embora seja notório que o Breviário de Braga que usa não é mais, por vezes, do que uma cópia dos textos compostos por Resende para o de Évora, não abdica de citar ambos os breviários, como se a concordância das duas fontes fornecesse um suplemento de autoridade. As limitaçóes que a Igreja desde muito cedo impôs aos textos que poderiam ser aceites na liturgia, de que o Decreto pseudo-Gelasiano é expressáo, estão na origem do crédito atribuído aos breviários. Uma vez neles incluídas, as narrativas tornam-se históricas, mesmo que as suas origens sejam obscuras e recentes.

O espírito acrítico com que Diogo do Rosário usa estas fontes mostra bem quanto o seu universo mental ainda pertence aos tempos anteriores a Trento e, por outro lado, prenuncia a fragilidade destas decisóes conciliares, que serão revertidas na influência que a tendência efabulatória dos falsos cronicóes exerceu nos breviários bracarenses do séc. XVII (Ferreira 1924: 209-211), de novo invadidos pelo maravilhoso e pelas falsas prerrogativas regionais.

A compilação hagiográfica de Fr. Diogo do Rosário representou, de facto, não só cronologicamente como pelas circunstâncias da sua produção, uma oportunidade para adequar aos princípios de Trento o legendário português, ultrapassando a tradição medieval. Se, apesar das alegaçóes do proémio, não foi exatamente isso que aconteceu, haverá que considerar a importância que estes textos tinham na leitura dos leigos justamente por serem romanescos e maravilhosos. Retirar-lhes esses elementos arriscaria perder o público e a capacidade de junto dele influir.

nis Praedicatorum, recognita, infinitisque mendis repurgata; adiectis denuò, praeter historiariam Lombardicam, aliquot Sanctorum Sanctarumque uitis, antehac non excusis.»

13. A credibilidade de Pedro de Natalis fora posta em causa: «non tardarono a diffondersi riserve più o meno motivate sul suo valore storiografico, la prima delle quali si legge nella rassegna bibliografica premessa da Jan Was (1511-1561) al Chronici rerum memorabilium Hispaniaetomus prior.» (Paoli 2012). 


\section{Bibliografia}

AASS = Acta Sanctorum, Fevereiro II, Paris e Roma, Victor Palmé, 1865.

Antonino de Florença, Historiarum Domini Antonini Archipresulis Florentini in tribus tomis discretarum . . cum triplice indice, Lugduni, Jacobus Myt, 1527.

AragüÉs AldAZ, José, «La Leyenda de los Santos: orígenes medievales e itinerario renacentista", Memorabilia, 18, 2016, 133-187.

Askins, Arthur L.-F., Harvey Sharrer, Martha Schaffer, et alii, Bibliografia de Textos Antigos Galegos e Portugueses, California-Berkeley, Bancroft Library, 6/12/2016, <http://bancroft.berkeley.edu/philobiblon/bitagap_en.html>.

Barbosa, D. Sampaio, "Portugal em Trento: uma presença discreta», Lusitania Sacra, 3, 1991, 11-38.

—, «Stimulus Pastorum: texto e contexto de uma proposta de renovação", Lusitania Sacra, 2a série, 15, 2003, 15-41.

$\mathrm{BHL}=$ Bibliotheca Hagiographica Latina antiquae et mediae aetatis, I-II, Bruxelles, ediderunt Socii Bollandiani, 1898-1899.

Boesch-Gajano, S., "La raccolta di vite di santi di Luigi Lippomano: storia, struttura, finalità di una costruzione agiografica», Raccolte di vite di santi dal XIII al XVIII secolo. Messaggi, strutture, fruizioni, a cura di S. Boesch Gajano, Fasano di Brindisi, Schena, 1990, 110-130.

Breviarium Braccarense, Braga, João Gherlinc, 1494.

Breuiarium bracharense, Braga, João Álvares e João de Barreira, 1549.

Breuiarium Eborense, Lisboa, Luís Rodrigues, 1548 (<http://purl.pt/22944>).

Breuiarium secundum consuetudinem Sancte Elborensis ecclesie, Sevilha, Jacobo Cromberger, 1528.

Canones, et Decreta Sacrosancti Oecumenici, et Generalis Concilij Tridentini, Sub Paulo III, Iulio III, et Pio IIII, Pontificibus Maximis: Index Dogmatum, \& reformationis, Olyssippone, apud Franciscum Corream, 1564: <http://purl. $\mathrm{pt} / 23051>$.

Castro, M. Fátima, «Devoçóes ligadas à igreja da Misericórdia e Sé Primaz de Braga. Documentação exemplificativa», Via Spiritus, 7, 2000, 163-201.

Cathecismo ou doutrina christäa \& praticas spirituaes. Ordenado por Dom Frey Bartholameu dos Martyres Arcebispo \& senhor de Braga Primas das Espanhas, Braga, Antonio de Mariz, 1564.

De GaIffier, B., «Le bréviaire d'Évora de 1548 et l'hagiographie ibérique», Analecta Bollandiana, 60, 1942, 131-139.

—, "Un prologue hagiographique hostile au Décret de Gélase?», Analecta Bollandiana, 82, 1964, 341-353.

DíAz y DíAz, M. C., et alii, Hislampa: hispanorum index scriptorum latinorum medii posteriorisque aeui: autores latinos peninsulares da época dos descobrimentos, 1350-1560, Lisboa, Imprensa Nacional-Casa da Moeda, 1993.

Dовsснüтz, Ernst von, ed., Das Decretum Gelasianum de libris recipiendis et non recipiendis in kritischem, Leipzig, J.C. Hinrichs, 1912. 
Fernández Catón, J.M., San Mancio: culto, leyenda y reliquias: ensayo de crítica hagiográfica, León, Centro de Estudios e Investigación San Isidoro, CSIC-CECEL, 1983.

Ferreira, José Augusto, Estudos histórico-litúrgicos. Os ritos particulares das Igrejas de Braga e Toledo, Coimbra, Coimbra Editora, 1924.

Ho Flos Sanctorum em lingoagé portugues, Lisboa, Hermão de Campos e Roberto Rabelo, 1513.

Jacobi a Voragine, Legenda Aurea vulgo Historia Lombardica dicta, ed. Th. Graesse, 2a ed., Lipsiae, Librariae Arnoldianae, 1850.

Iacopo da Varazze, Legenda Aurea, edizione critica per Giovani Paolo Maggioni, Firenze, Silmel, 2000.

Jedin, Hubert, História del Concílio de Trento. 4. Tercer periodo: conclusion, vol. 2: Superación de la crisis. Conclusión y ratificación, Pamplona, Universidad de Navarra, 1981.

La Leyenda de los Santos, Burgos, Juan de Burgos, 1500.

Lippomano, Luigi, Historiae Aloysii Lipomani, episcopi veronensis de vitis sanctorum. Lovanii, apud Martinum Verhasselt, 1565.

Mimouni, S. Claude, Les traditions anciennes sur la Dormition et l'Assomption de Marie. Études littéraires, historiques et doctrinales, Leiden-Boston, Brill, 2011, 247-256.

Missale secundum consuetudinem Elborensis Ecclesie nouiter impressum, Lisboa, Germão Galhardo, 1509.

Oliverra, Miguel de, «Livros Litúrgicos de Évora», Lusitania Sacra, 6, 1962/63, 263-274.

—, Lenda e História. Estudos Hagiográficos, Lisboa, União Gráfica, 1964.

PAoli, Emore, «Natali, Pietro de», Dizionario Biografico degli Italiani - Volume 77, 2012, 6/12/2016, <http://www.treccani.it/enciclopedia/pietro-de-natali_(Dizionario-Biografico) $>$.

Resende, André de, Officium Divi Gundisalvi, Coimbra, João Álvares, 1562/63 (1562 rosto, 1563 cólofon).

Rosa, M. Lourdes, "Hagiografia e Santidade», Dicionário de História Religiosa de Portugal, dir. C. Moreira de Azevedo, Lisboa, Círculo de Leitores, 2000, vol. C-I, 326-361.

Rosário, Diogo do, Historia das vidas \& feitos heroicos \& obras insignes dos sanctos: com muitos sermóes \& praticas spirituaes que seruem a muitas festas do anno reuistas \& cotejadas có os seus originaes, Braga, em casa de Antonio de Mariz, 1567.

SÃo Domingos, António de, Compêndio de religiosos insignes da ordem dos pregadores, Coimbra, João de Barreira e João Álvares, 1552.

Sanctorum priscorum patrum vitae: per gravissimos et probatissimos avctores conscriptae. quae instante R.P.D. Aloysio Lipomano, Episcopo Veronensi, nunc primum ex Symeone Metaphraste Graeco auctore latinae factae sunt, vols. I-V, Veneza, Al segno della speranza, 1551-56; VI, Roma, ex officina Salviana, 1558; VII-VIII, Roma, A. Blado, 1558 e 1560. 
Sobral, Cristina, Adiçôes portuguesas no Flos Sanctorum de 1513, tese de doutoramento apresentada à Faculdade de Letras de Lisboa, 2000.

Summa caietana tresladada em portugues, com muytas annotaçóes \& casos de consciencia \& decretos do sagrado concilio tridentino polo padre frey diogo do rozayro da ordem de sam domingos, Braga, Antonio de Mariz, 1565. 